\title{
HOW GAME AND GAME PRINCIPLES FACILITATE THE CO- DESIGN PROCESSES: REFLECTIONS ON TWO CASE STUDIES
}

\author{
Zhang, Ziheng; \\ Zurlo, Francesco
}

Politecnico di Milano

\begin{abstract}
The increasing need to motivate and engage participants in the co-design has led to the trend of employing game elements in the early phase of the design process to facilitate the activities. However, most have described the gamified co-design by its methods, purposes, and functions. How games theoretically contribute to achieving those goals is still uncovered. This research aims to bridge this theoretical-practical gap by first defining the game principles from the literature. Then investigate how those principles manifested in two case studies with detailed game elements. Finally, we present a framework that links the game principles and purposes/functions by reflecting the cases.
\end{abstract}

Keywords: Collaborative design, Case study, Design process, Early design phases

\author{
Contact: \\ Zhang, Ziheng \\ Politecnico di Milano \\ Design \\ Italy \\ ziheng.zhang.polimi@gmail.com
}




\section{INTRODUCTION}

The co-design approach is increasingly popular on many occasions for engaging stakeholders to understand challenges and generating solutions (Binder et al., 2008). It involves diverse participants with different backgrounds, experiences, and interests in exploring, developing, and prototyping to shared challenges. Thus, the fundamental challenge is to apply appropriate methods for engaging and involving participants (Anderson et al., 2015; Bratteteig \& Wagner, 2016). Towards this challenge, many scholars have explored the game metaphor as a way of organizing participation. Brandt (2006) emphasizes that the exploratory design game is a valuable framework for involving people with diverse expertise, interests, and professional languages. Vaajakallio \& Mattelmäki (2014) stress a play framework for codesign, in which design games function as a tool for designers, create a mindset for players, and a structure for further game designers. Patricio (2018) comments that the gamified design process could support high-quality solution creation in an open and creative environment and promotes co-design by providing a peer-to-peer structured game approach that enhances the interaction between different participants. This study is based on these studies and assumes that gamified activities can significantly facilitate participants' engagement and motivation towards co-design.

Although many have described the functions and purposes of game-based tools, techniques, and methods for facilitating co-design, researchers have yet to analyze in detail how to migrate games into a design-oriented context and service for co-design. This gap leads to the blind copy of games, obscures user perception, and finally causes disengagement. This study contributes to bridging this gap by linking the purpose of co-design and the principles of games. We first summarize the goals and purposes of gamifying co-design processes through the literature review. Then we define the "game principles" from game studies that have the potential to facilitate co-design and investigate the application of game principles in the co-design in two case studies. Finally, we generate hypotheses from the case studies that illustrate game principles' contribution to co-design activities.

\section{LITERATURE REVIEW}

Historically, co-design is a variant of "participatory design (PD)" that emerged in the early 1970s in the Scandinavian countries. PD motivated designers to involve people in policy-making to empower end-users to catalyze democratic empowerment (Halskov \& Hansen, 2015). Over the years of development, it derived various forms and concepts, including co-design and co-creation. Currently, the idea of "co-design" (and related terms) has developed into a practical design approach that facilitates collective creativity and stakeholder involvement. Sanders and Stappers (2008) issued the concept of "co-creation." It is referred to as "collective creativity, i.e., creativity shared by two or more people." To narrow down the implication, they stressed the term "co-design" to refer to the collective creativity applied only across the span of a design process.

\subsection{Gamifying the process for fuzzy front-end}

Although scholars often claim that users should involve (in co-design) throughout the whole design process at all critical moments of making decisions (Sanders \& Stappers, 2008), the majority of cases that have been published are focus on the importance of the early phases of the design process (Almqvist, 2017), which is often referring to the "fuzzy front-end (Smith \& Reinertsen, 1998)". Many efforts to describe and visualize the design process into structured models (Designthinkers, 2009). One of the most cited models is the "Double diamond design process" (Design Council, 2015). It divided the generic design process into four stages: discover, define, develop, and deliver. The first two stages are often described as the "fuzzy front-end" because of the involvement of "ad hoc decisions and illdefined processes" (Montoya-Weiss \& O'Driscoll, 2000). The gamified activities are significantly prevalent in the "fuzzy front-end" of co-design activities (Patrício, et al., 2018).

Zhang \& Zurlo (2020) present a systematic review regarding the definition and facilitation of "participants engagement" in 81 recent co-design-themed publications. The study reveals that processes embed the principle of "game \& play" accounts for most methods for engaging participants. It includes the employment of board/card games (also known as design games), toy pieces, serious playing, and role-playing, etc. Most literature introduces them regarding their purpose and function as we present (Table 1) (Vaajakallio \& Mattelmäki, 2014; Brandt, 2006; Brandt, 2010; Patrício, et al., 
2018; Habraken \& Gross, 1987; Iversen, \& Buur, 2002). However, few studies discuss how games contribute to achieving those goals.

Table 1. The purposes and functions of gamified co-design processes from literature

\begin{tabular}{|c|c|c|}
\hline \multicolumn{2}{|l|}{ Purpose } & Function \\
\hline \multirow{9}{*}{$\begin{array}{l}\text { Facilitate } \\
\text { participants } \\
\text { engagement }\end{array}$} & \multirow{3}{*}{$\begin{array}{l}\text { To interest/immerse } \\
\text { participants }\end{array}$} & $\begin{array}{r}\text { To immerse the players in envisioning and } \\
\text { enacting. }\end{array}$ \\
\hline & & To create an entertaining design atmosphere. \\
\hline & & $\begin{array}{l}\text { To transport participants into a "magic } \\
\text { circle" as a physical and ideal playground. }\end{array}$ \\
\hline & \multirow{3}{*}{ To empower participants } & To build design competence. \\
\hline & & Help to define the roles of participants. \\
\hline & & $\begin{array}{r}\text { To create an equal and open playground for } \\
\text { discussions. }\end{array}$ \\
\hline & \multirow{3}{*}{ To arouse participants } & To exchange perspectives. \\
\hline & & $\begin{array}{r}\text { To promote a creative and explorative } \\
\text { attitude. }\end{array}$ \\
\hline & & $\begin{array}{r}\text { To understand the context through } \\
\text { negotiation. }\end{array}$ \\
\hline \multirow{3}{*}{$\begin{array}{l}\text { Facilitate the } \\
\text { design } \\
\text { process }\end{array}$} & \multirow{2}{*}{ Organize workflow } & $\begin{array}{c}\text { To provide a structural setting (keep own } \\
\text { turn, keep time limits, etc.) }\end{array}$ \\
\hline & & To create positive tension. \\
\hline & $\begin{array}{l}\text { Define the design } \\
\text { challenges }\end{array}$ & $\begin{array}{l}\text { To conceptualize design challenges in a safe, } \\
\text { alternative game world. }\end{array}$ \\
\hline
\end{tabular}

\subsection{Game principles}

Many have proposed their suggestion regarding how the games are engaging, most by analyzing the game elements as the basic building blocks of games. However, each game is largely different. The frameworks committed to clarifying elements of design-oriental games are often somewhat arbitrary and subjective. Instead, we extract the "game principles" from the most cited and recognized theories and definitions as a framework for understanding the general game's contribution towards players' engagement and motivation.

Huizinga (1950) pictures the "game" as a "magic circle," he emphasized the game places are full of fantasy and restricted by their rules. Salen \& Zimmerman define Playing a game as "free movement within a more rigid structure" (Salen \& Zimmerman, 2004). Similar definitions as "A game is a closed, formal system that engages players in a structured conflict, and resolves in an unequal outcome." (Fullerton, 2014). Mallaby (2007) describes the game as "a ... domain of contrived contingency that generates interpretable outcomes" This coincides with the famous words of Sid Meier, "A game is a series of meaningful choices." At a philosophical level, Suits (2014) claimed playing a game is "voluntarily overcoming unnecessary obstacles(challenges)." In his definition, a 
game is the combination of pre-lusory goals, constitutive rules, and lusory attitude. We distinguish these core definitions as the game principles to guide the gamified design process in general.

- Fantasy aesthetic: A fantasy aesthetic could make a massive contribution to players' first impression of a game. It meets the individual's tendency to think and play in a fantastical world and plays an essential role in determining whether players want to play the game. As the antonym of "every day," it allows players to experience things that would never really happen (Schwartz, 2006; Malone \& Lepper, 1987; Sharon \& Woolley, 2004)

- Game rules: Rules can guide and restrict players' behavior, creating interactions (Salen \& Zimmerman, 2004). They are often the embodiment of game mechanics that describes "what the players can do in the game-world, how they do it, and how that leads to a compelling game experience" (Sicart, 2008). Rules are often designed for players to overcome challenges. Designers create the basic rules for the player correlating the challenges with the set of mechanics helpful in solving them.

- Challenge: Challenges are one of the central principles in game research. It refers to a set of situations in which the player's game result requires an effort to accomplish (Sicart, 2008). The set challenges could create "motivational tension" (Driskell \& Dwyer, 1984) if they match the players' abilities and skills. Otherwise, it will lead to boredom or frustration (Chen, 2015; Douglas \& Hargadon, 2000).

- Meaningful choice: It implicates players' choices can lead to different and interpretable results (Salen and Zimmerman, 2003). it manifests in two aspects. Awareness: a player must be informed of what choices he/she can make. Consequences: the player's choices must be accurately represented in the game.

- Lusory attitude: It refers to the players' attitudes and mindsets of whether they will play the game according to its rules and to the best of their abilities freely. It also implicates voluntarism, the "voluntary attempt to overcome unnecessary obstacles." (Suits, 2014)

In the next section, we identify the game principles manifested in two cases and investigate how those principles contribute to participants' engagement.

\section{CASE STUDIES}

\subsection{Case 1: Participatory game design with children}

Psychology and education studies reveal that games are the most attractive to children. There are many attempts to apply games for children's education and training(Human et al., 2017). Co-design activities have also been considered competence-relevant activities in need of children learning from design activities and gradually mastering the design tasks. We implemented a participatory game design workshop with children to investigate whether a gamified activity can facilitate childrens' engagement and co-design processes.

The workshop was run in January of 2020 in a primary school located in Changzhou, China. We involved a total of 34 children (grade 3, age: 8-9 years) who participated voluntarily. Their class teacher and two assistants are also involved as facilitators. The workshop aims to engage children to co-design the early stage of an educational math game. Due to the relatively short time (70 minutes total) and the messy nature of the "early stage of design," the children were expected only to design the main game characters. Supporting materials were introduced, including eight different real fruits for each group, 6 attribute cards, 5 role-play cards, and 4 blank inspiration cards (story/character/ avatar/item card) for each child. Each group of children is expected to pick one kind of fruit as their main character. By role-playing and filling (drawing and writing) the blank parts of inspiration cards, finally generate an anthropomorphic game character and his/her story (Figure 1).

We collected and analyzed a large amount of qualitative data, including observation recording, video recording, interview of children, and interview of their teachers. The data shows that the gamified codesign activities result in a higher-level engagement than their regular classes. Symptoms caused by immersion and flow have appeared, e.g., weakened ability to perceive time. Six out of seven groups completed their "fuzzy" design challenge before the end of the workshop. This completion degree shows that children were empowered more competence to overcome a design challenge. The detailed data presentation and analysis are beyond the scope of this paper. Here we are focusing on a hypothetical explanation of how the gamified activities achieved those goals by applying "game principles." 


\subsubsection{Gamified Design Method}

Children were divided into groups based on their preference for each fruit. Each child shall select a role to play according to his/her willingness and skills. Once the group determines the character's basic information. Each player can deliver 2 attribute cards representing 2 points of the character's strength/intelligence/dexterity. The Captain can adjust the final attributes up to 2 points. Based on the distributed attributes, children start to design their characters in detail. Despite the divided work, the overall design activity is encouraging collaboration. For example, the storyteller's story must fit the artist's drawing, vice versa. The design objective (design the portraits/stories/items of characters), fantasy elements(role-play), and the player behaviors(drawing, writing, discussing) are reasonably unified and influence each other.

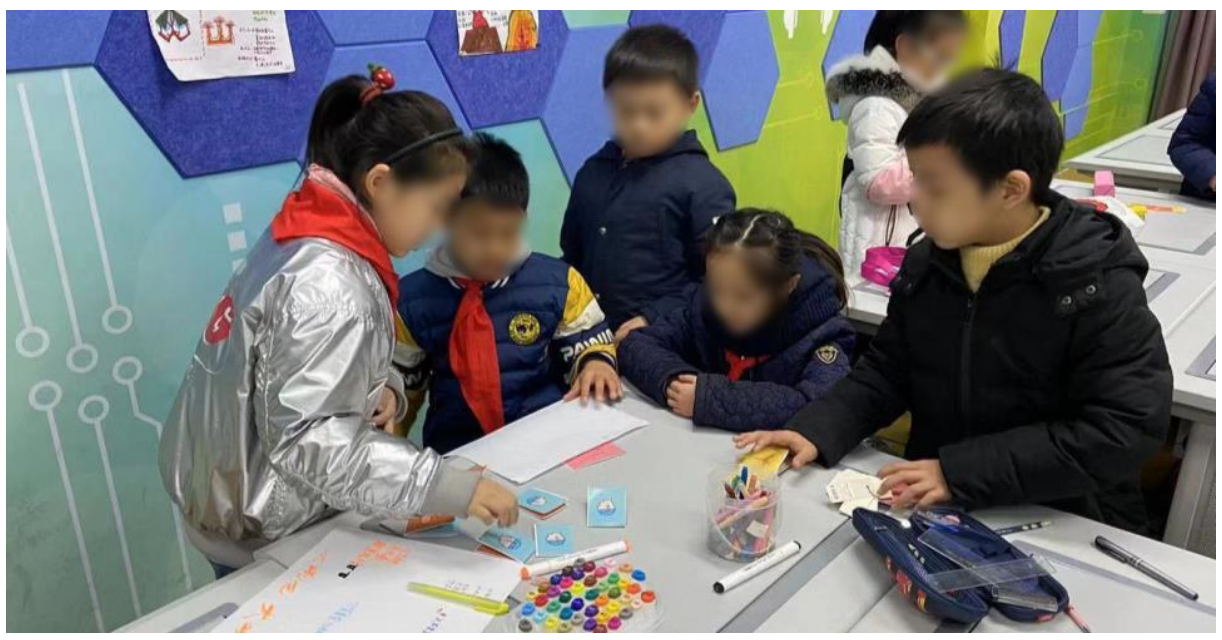

Figure 1. Children are engaging in co-design

\subsubsection{Reflections regarding game principles and purposes}

We identify three game principles in this case that contribute the most to achieve the goals (Table 2).

- Fantasy aesthetic: The design of supporting materials intent to trigger "fantasy proneness": enhances one's willingness to engage in imaginary activities. In the ice-breaking section, facilitators use the game "zombie vs plants" as a portrayal fantasy reference to explain the design objective. In the role-play section, children choose their fantasy representation to join the collaboration. The fantasy elements have led players into a playground that is very different from their everyday life. In this case, fantasy elements contribute hugely to children's engagement through creating an entertaining atmosphere, create an equal place for discussions, and promote a creative and explorative attitude.

- Rules: The basic rule of the activities is role-playing. It helps to define the roles of children and promote a creative and explorative attitude. During the role-play collaboration, children must follow the order and respect the time limits. It provides a structural setting that prevents confusion and time wasted.

- Challenges: Despite the design activity is quite challenging, the researchers still purposely set an additional challenge - calculating three additional attributes (Carrying capacity, speed, memory), which need an unfamiliar formula to do the calculation. The observation shows that more than half of the children are confusing. Several children raised their hands to seek help on this challenge and showed nervousness while waiting. This over-skill challenge led to more frequent signs of disengagement. In contrast, many children showed time-insensitive during match-skill challenges, such as free drawing head portraits for their characters.

- Lusory attitude: Voluntarism is vital in this case. We give the children complete freedom to choose whether to participate in this activity and treat them as "experts of their life" instead of primary school students. 
Table 2. Reflections on game principles and purposes in case 1

\begin{tabular}{|c|c|c|}
\hline $\begin{array}{l}\text { Game } \\
\text { principles }\end{array}$ & & Purpose of gamifying \\
\hline \multirow{3}{*}{$\begin{array}{l}\text { Fantasy } \\
\text { aesthetic }\end{array}$} & & To create an entertaining and relaxing atmosphere \\
\hline & & To immerse players in envisioning \\
\hline & & To promote a creative and explorative attitude \\
\hline \multirow{3}{*}{ Rules } & \multirow{2}{*}{ Role-play } & To define the roles of participants \\
\hline & & To create an equal and open place for discussions \\
\hline & structural rules & To provide a structural setting \\
\hline \multirow{2}{*}{ Challenges } & \multirow{2}{*}{$\begin{array}{l}\text { Match-skill } \\
\text { challenges }\end{array}$} & To build design competence \\
\hline & & To immerse players in enacting \\
\hline $\begin{array}{l}\text { Lusory } \\
\text { attitude }\end{array}$ & & To facilitate the voluntary engagement \\
\hline
\end{tabular}

\subsection{Case 2: Gamified workshops for hygienic water challenge}

Instead of engaging children who are quickly immersed in game\&play. We present another entrepreneurial case with a relatively universal structure: A co-design workshop with adult designers orchestrated through gamification. The workshop was run in May of 2019 in Politecnico di Milano. Company Uponor sponsored it aims to explore a new solution to ensure the safety of the water supply. The workshop was a half-day co-design event involving 35 young professionals as co-designers. A gamification tool called "ideaChef" was used to facilitate collaboration. We collected the self-report data from questionnaires and afterward interviews. The data shows that gamified co-design has resulted in higher engagement and excellent solution generation (ranked by challenge owners and experts). The detailed data analysis is beyond the scope of this paper. We are still focusing on a hypothetical explanation of how the gamified activities achieved these goals by applying "game principles."

\subsubsection{Gamified Design Method}

The "IdeaChef" method is composed of three phases: setup, play, and report. Due to the scope of this paper, we only focus on the phase of play." provides a creativity-oriented board game to facilitate the play section. The game metaphorized cooking as the design process, requiring players to deliver their "ingredients" and "recipes" to shape the design concept (Patricio. et al., 2020). At the beginning of every round, each player should roll the dice to get a random question card from 6 dimensions (ingredients, recipes, taste, etc.) After answering the question, one player shall introduce his/her contribution and rate the others. The game lasts around 6 rounds, and a mature solution will ideally be generated. Although the game reduces conflict between players, it is still a "winner" in each group who earns the most rated points (Figure 2). 


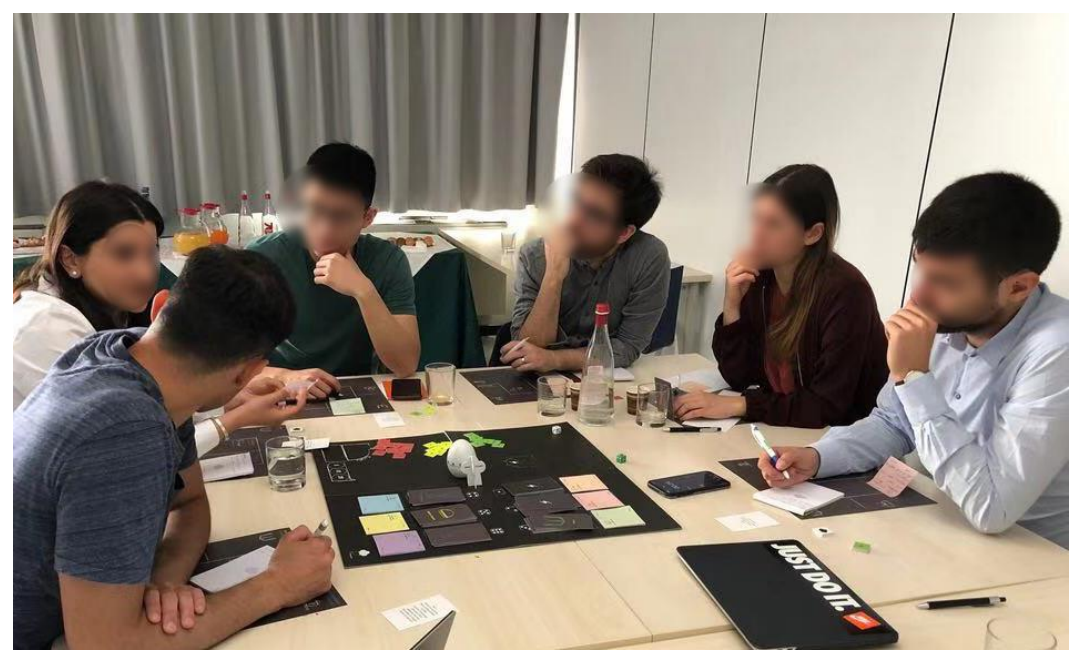

Figure 2. Participants playing "IdeaChef" board game

\subsubsection{Reflections regarding game principles and purposes}

We identify 4 game principles in this case that contribute the most to achieve the goals (Table 2).

- Fantasy aesthetic: Fantasy is defined as the opposite of "everyday life" in the previous section. Although cooking is expected in one's life, it is still far from typical "everyday" design activities. The cooking metaphor functions to transport participants into a fantasy "magic circle" as a safe place where players could explore the solution beyond current situations' bondage. Participants could conceptualize design challenges in a safe, alternative game world. The metaphor also contributes to building participants' design competence. The question cards can guide participants to go deep into a particular dimension of the solution.

- Rules: The rules and mechanics are essential to make this activity well-structured. Rules requiring users to answer different questions within a limited time period and dice could ensure that all question cards are randomly selected. The execution of the game relies on the rate mechanic. Players should listen and discuss with others to rate their contributions. It offers a platform to exchange perspectives between participants and let them understand the design context through negotiation.

- Conflict: Although the game intentionally weakens the competition between players and groups, it still results in a winner who earns the most points. The slight conflict between players could create positive tension and raise positive emotions to invoke recognition, happiness, and creativity.

- Meaningful choice: Players could choose and rate the most valued solutions. It offers an opportunity to select out the most potential solution.

Table 3. Reflections on game principles and purposes in case 2

\begin{tabular}{|c|c|c|}
\hline $\begin{array}{l}\text { Game } \\
\text { principles }\end{array}$ & & Purpose of gamifying \\
\hline \multirow{3}{*}{$\begin{array}{l}\text { Fantasy } \\
\text { aesthetic }\end{array}$} & \multirow{3}{*}{ Cooking metaphor } & $\begin{array}{r}\text { To transport participants into a "magic circle" as an ideal } \\
\text { playground }\end{array}$ \\
\hline & & $\begin{array}{r}\text { To conceptualize design challenges in a safe, alternative } \\
\text { game world. }\end{array}$ \\
\hline & & To build design competence among players. \\
\hline \multirow{3}{*}{ Rules } & \multirow{2}{*}{ Rating } & To understand the context through negotiation. \\
\hline & & To exchange perspectives between participants. \\
\hline & structural rules & To provide a structural setting. \\
\hline Conflict & competition & To create positive tension. \\
\hline \multicolumn{2}{|c|}{ Meaningful choice } & To select out the most potential solutions. \\
\hline
\end{tabular}




\subsection{Overview functions of game principles}

By synthesis the above cases, we point out each game principle's main contribution to co-design activities(Figure 3). This preliminary framework could be a guideline for organizing gamified codesign activities or/and the design of gamified tools for co-design.

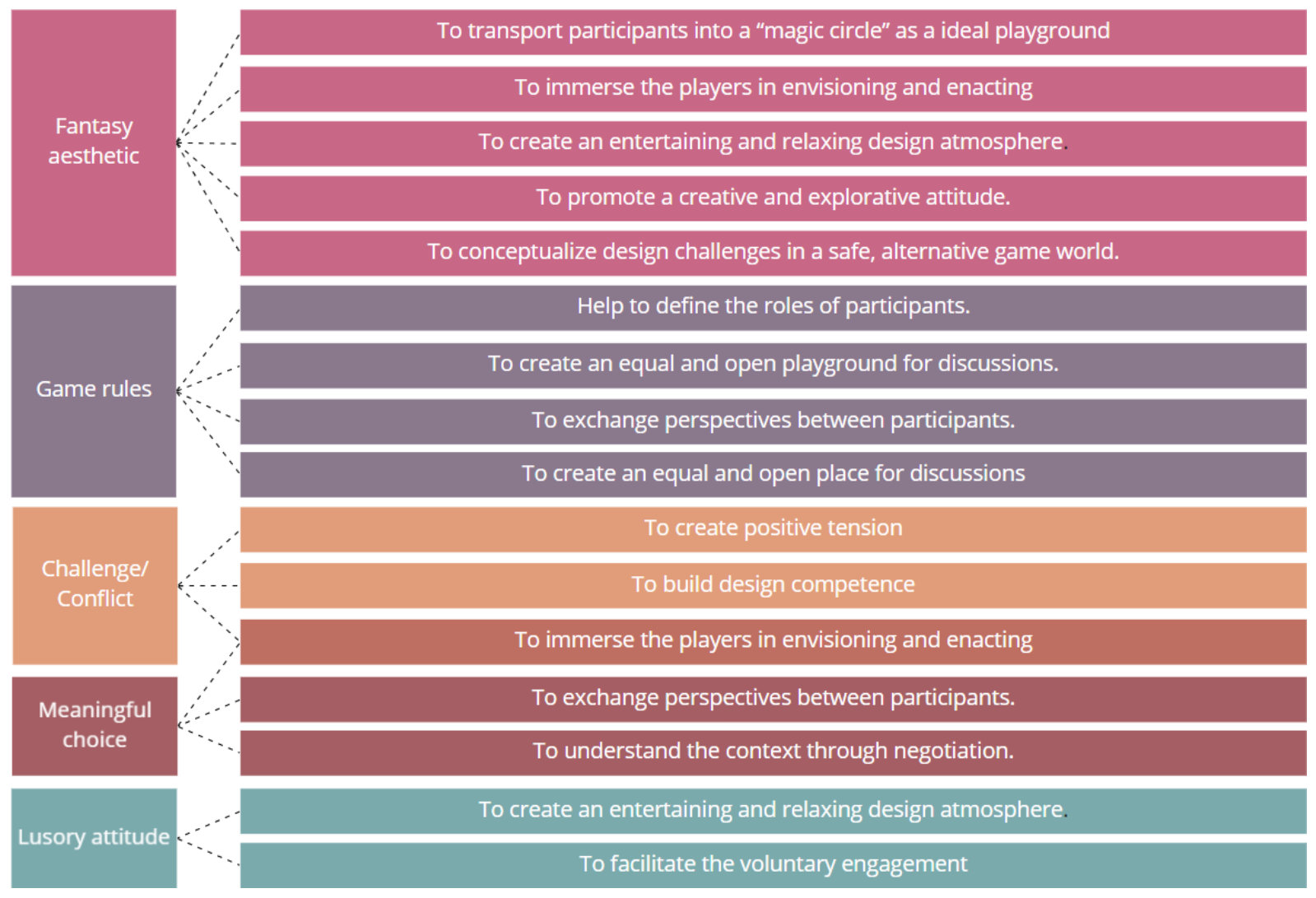

Figure 3. Main contributions of game principles

\section{CONCLUSION, CHALLENGES, AND FUTURE WORK}

In this paper, we identified the principles of games that have the potential to facilitate the early stages of co-design activities for different purposes.

The literature review shows that even though the gamified co-design approach has served many different fields with different participants, the purposes of designers gamifying the process are analogous. One reason is that the most reported cases consistently focus on the early stage of the design process. After gathering the purposes of gamifying, we define several game principles from game studies literature. Finally, by investigating two cases, we synthesize a preliminary framework that bridges the game principles and their potential contribution to different co-design purposes.

This study has several challenges and limitations. It is a challenge to discuss two cases together with quite different participants, methods, and design objectives, even though there is significant consistency in two cases regarding the reflections of game principles. Another challenge is to evaluate the quality of the outcome designed (especially case 1). It isn't easy to assess the design outcome in such an experiential project accurately.

The first limitation is that our case studies examined only two kinds of participants and organizational perspectives; they cannot be expected to cover all possible differences. Also, there is a lack of comparison of the design outcome between gamified and non-gamified co-design approaches. Despite there being sufficient evidence to show that embracing game principles can greatly facilitate engagement towards participants, it is still uncovered the relationship between games and the quality of design outcomes. Last but not least, the facilitators' contributions were also significant in both cases. However, it is a challenge to separate the contributions of the game principles from facilitators. 
The framework provides a range of implications for future research. In addition to testing our theory in wider socio-cultural settings, it is necessary to experiment and examine the contribution of each game principle as well as examine the participants' perception.

\section{REFERENCES}

Almqvist, F. (2017) 'The fuzzy front-end and the forgotten back-end: User involvement in later development phases', The Design Journal. Taylor \& Francis, 20(sup1), pp. S2524-S2533.

Andersen, L. B. et al. (2015) 'International Journal of CoCreation in Design and the Arts Participation as a matter of concern in participatory design', CoDesign. Taylor \& Francis, 0882, pp. 1-12. https://dx.doi.org/10.1080/15710882.2015.1081246.

Binder, T., Brandt, E. and Gregory, J. (2008) 'Design participation(-s) - a creative commons for ongoing change', CoDesign, 4(2), pp. 79-83. https://dx.doi.org/10.1080/15710880802114458.

Brandt, E. 2010. "Playing Design Games: Programmatic Vision." In Rehearsing the Future, edited by J. Halse, E. Brandt, B. Clark, and T. Binder, 131-134. Copenhagen: The Danish Design School Press.

Brandt, E., 2006, August. Designing exploratory design games: a framework for participation in participatory design?. In Proceedings of the ninth conference on Participatory design: Expanding boundaries in designVolume 1 (pp. 57-66).

Bratteteig, T., \& Wagner, I. (2016). Unpacking the Notion of Participation in Participatory Design. Computer Supported Cooperative Work: CSCW: An International Journal, 25(6), 425-475. https://doi.org/10.1007/s10606-016-9259-4.

Chen, J. (2015) 'Flow in Games - a Jenova Chen MFA Thesis', pp. 18-24. https://doi.org/10.1145/1232743.1232769.

Design Council. (2015). Innovation by design: How design enables science and technology research to achieve greater impact. http://www.designcouncil.org.uk/sites/default/files/asset/document/innovation-by-design.pdf

Designthinkers.(2009).5 steps service innovation method. http://designthinkers.blogspot.no/2009/01/5-stepsservice-innovation-method.html.

Douglas, Y., \& Hargadon, A. (2000). The pleasure principle: immersion, engagement, flow. In Proceedings of the eleventh ACM on Hypertext and hypermedia (pp. 153-160).

Driskell, J. E. and Dwyer, D. J. (1984) 'Microcomputer videogame based training', Educational technology. JSTOR, 24(2), pp. 11-16.

Elizabeth B.-N. Sanders \& Pieter Jan Stappers (2008) Co-creation and the new landscapes of design, Co-Design, 4:1, 5-18, https://dx.doi.org/10.1080/15710880701875068.

Fullerton, T. (2014) Game design workshop: a playcentric approach to creating innovative games. CRC press.

Habraken, H. J., and M. D. Gross. 1987. Concept Design Games (Book 1 and 2). A report submitted to the National Science Foundation Engineering Directorate, Design Methodology Program, Department of Architecture, MIT, Cambridge, MA, 02139.

Halskov, K. and Hansen, N. B. (2015) 'The diversity of participatory design research practice', Journal of Human Computer Studies. Elsevier, 74, pp. 81-92. https://dx.doi.org/10.1016/j.ijhcs.2014.09.003.

Huizinga, J. 1950. Homo Ludens: A Study of the Play Element in Culture. Boston, MA: Beacon Press, Roy Publishers.

Human, I. J. et al. (2017) 'Children's emotions and quality of products in participatory game design', Journal of Human Computer Studies. Elsevier Ltd, 101(December 2016), pp. 45-61. https://dx.doi.org/10.1016/j.ijhcs.2017.01.006.

Iversen, O. S., and J. Buur. 2002. "Design is a Game: Developing Design Competence in a Game Setting." In Proceedings of Participatory Design Conference (PDC'02), 22-28. Malmo“: CPSR.

Malaby, T. M. (2007) 'Beyond play: A new approach to games', Games and culture. Sage publications Sage CA: Los Angeles, CA, 2(2), pp. 95-113.

Malone, T. W. and Lepper, M. R. (1987) 'Making Learning Fun, A Taxonomy of intrinsic Motivations for Learning.', pp. 223-253.

Montoya-Weiss, Mitzi M., \& O’Driscoll, Tony M. (2000). From experience: Applying performance support technology in the fuzzy front-end. Journal of Product Innovation Management, 17(2), 143-161.

Patrício, R., Moreira, A. C. and Zurlo, F. (2018) 'Gamification approaches to the early stage of innovation', Creativity and Innovation Management, 27(4), pp. 499-511. https://dx.doi.org/10.1111/caim.12284.

Patricio, R. et al. (2020) 'Co-creation of new solutions through gamification: A collaborative innovation practice', Creativity and Innovation Management, (November 2019), pp. 146-160. https://dx.doi.org/10.1111/caim.12356.

Patrício, R. and Morozumi, R. (2018) 'Gamification for service design and Innovation: ideaChef® method and tool', ServDes2018 - Service Design Proof of Concept, (June), p. 16.

Porcini, M. (2009) 'Your new design process is not enough — hire design thinkers!', Design Management Review. Wiley Online Library, 20(3), pp. 6-18.

Salen, K., and E. Zimmerman. (2004). Rules of Play: Game Design Fundamentals. England: MIT Press. 
Salen, K. and Zimmerman, E. (2003)' Game Design and Meaningful Play’, Rules of Play: Game Design Fundamentals, pp. 59-79.

Schwartz, L. (2006) 'Fantasy, realism, and the other in recent video games', Space and Culture, 9(3), pp. 313-325. https://dx.doi.org/10.1177/1206331206289019.

Sharon, T. and Woolley, J. D. (2004) 'Do monsters dream? Young children's understanding of the fantasy/reality distinction', British Journal of Developmental Psychology. Wiley Online Library, 22(2), pp. 293-310.

Sicart, M. (2008) 'Defining game mechanics', Game Studies, 8(2), p. n.

Smith, P. G. and Reinertsen, D. G. (1998) Developing products in half the time: new rules, new tools. Van Nostrand Reinhold New York.

Smith, P. G. and Reinertsen, D. G. (1998) 'Faster to market', Mechanical Engineering. American Society of Mechanical Engineers, 120(12), pp. 68-70.

Suits, B. (2014) The Grasshopper-: Games, Life and Utopia. Broadview Press.

Vaajakallio, K. and Mattelmäki, T. (2014) 'International Journal of CoCreation in Design and the Arts Design games in co-design : as a tool, a mindset and a structure', CoDesign. Taylor \& Francis, pp. 63-77. https://dx.doi.org/10.1080/15710882.2014.881886. 